\title{
Methodology for the development of a new Sustainable Infrastructure Rating System for Developing Countries (SIRSDEC)
}

\author{
Jose Manuel Diaz-Sarachaga, Daniel Jato-Espino, Daniel Castro-Fresno* \\ GITECO Research Group, Universidad de Cantabria, Avd. de los Castros s/n, 39005 Santander, Spain \\ E-mail addresses: jose-manuel.diazs@alumnos.unican.es (J.M. Diaz-Sarachaga); daniel.jato@unican.es (D. \\ Jato-Espino); daniel.castro@unican.es (D. Castro-Fresno) \\ * Corresponding Author: Tel: +34 942 201550; Fax: +34 942201703
}

\begin{abstract}
The improvement of infrastructures in developing countries has become a priority for the most advanced economies, which have founded a broad range of international development organizations to undertake infrastructure projects worldwide. Infrastructure is the key driver that can accelerate the balance among the economic, social and environmental aspects forming the Triple Bottom Line (TBL) in these countries. Given the lack of appropriate tools to ensure the achievement of this goal, this paper describes the methodology conceived for the development of a Sustainable Infrastructure Rating System (SIRSDEC) aimed at promoting the design, construction and operation of sustainable infrastructure projects in these geographical areas. SIRSDEC is structured into a hierarchical decision-making tree consisting of three levels of elements (requirements, criteria and indicators) selected to assess infrastructure systems according to sustainability principles. The methodology on which SIRSDEC is based combines the action of two multi-criteria decision-making methods (MCDM) such as the Analytical Hierarchy Process (AHP) and the Integrated Value Model for Sustainable Assessment (MIVES). AHP is proposed to weight the elements forming the decision-making tree after processing the opinions provided by a group of international experts regarding the importance of requirements, criteria and indicators, whilst MIVES is suggested to value infrastructure projects according to their contribution to the TBL. The article emphasizes the added value provided by the combination of AHP and MIVES in the design of an adhoc rating system aimed at fostering the implementation of sustainable infrastructure projects in developing countries.
\end{abstract}

\section{Keywords}

AHP; MCDM; MIVES; Rating System; Sustainable Infrastructure.

\section{Introduction}

The third of the 27 principles proclaimed in the final Declaration of Rio+20 United Nations Conference on Sustainable Development held in June 2012 stated that the right to development must be fulfilled to meet developmental and environmental needs of present and future generations. This principle reaffirmed the key role of sustainability in contemporary society and promoted the urgent need for developing effective frameworks to balance long-term economic, environmental and social aspects in construction processes (UN, 1992).

A sustainability rating system can be defined as a set of best practices that evaluates sustainability through the scoring of a series of indicators (Hart, 2006). Furthermore, this framework enables diverse indicators measured in different units (e.g. pollutants/carbon emitted to atmosphere, renewable energy used, recycled materials, energy consumption/conservation, ecosystem/biodiversity preservation, 
culture heritage maintenance, etc.) to be integrated into a single analysis aimed at rating infrastructure projects in terms of their contribution to sustainability.

Property industry was the pioneer in the development of sustainability rating systems for buildings in advanced economies, such as Leadership in Energy and Environmental Design (LEED) in the U.S. (USGBC, 2009), Building Research Establish Environmental Assessment Method (BREEAM) in the U.K. (BRE, 2014) and Comprehensive Assessment System for Building Environmental Efficiency (CASBEE) in Japan (IBEC, 2011). A few years later, the transportation community designed its own specific systems too. At present, there are a significant number of national and international rating systems oriented to evaluate green buildings and only a few focused on analysing infrastructures from the point of view of sustainable development. These systems vary in terms of scope and complexity but are generally designed to provide guidance, scoring and potential rewards for using sustainable best practices. Rating systems usually focus on practices that are compatible with current regulations but are beyond existing minimum regulatory requirements. The main purpose of most sustainability rating systems is not to set a scientifically defensible taxonomy of sustainability, but rather a tool to encourage the implementation of sustainability practices beyond regulatory minimum targets and communicate sustainability concepts in a comprehensible manner to all stakeholders, from construction professionals to citizens.

Rating systems are often criticized because they tend to minimize the appraisal of economic and social aspects in detriment of environmental issues (Gibberd, 2005). In addition, international development agencies and organizations have not broadly incorporated rating systems into the assessment of their project processes (UNOPS, 2012), whilst the evaluation of the economic benefits derived from their implementation is very complicated (FIDIC, 2012). In relation to the context of this research, rating systems are also deficient due to their focus on developed economies and omission of specific features of third world countries (EAP \& ARUP, 2011).

There are three main rating systems that assess infrastructure projects following the principles of sustainability: ENVISION (USA) (ISI, 2012), Civil Engineering Environmental Quality (CEEQUAL) (BRE Group, 2015) and Infrastructure Sustainability (IS) Rating Tool (Australia) (ISCA, 2012). A review of these rating systems revealed that they are imbalanced in relation to the importance given to the three pillars of sustainability, also known as the Triple Bottom Line (TBL), since the number of environmental credits considered are more numerous than those assigned to economic and social aspects (DiazSarachaga et al., 2016). Commercial reasons are the main goal of infrastructures rating systems in richer nations, in order to advertise the quality of projects and the interest of clients, designers and/or builders in sustainability, whereas the context of developing countries requires a different approach for evaluating the whole sustainability contribution of projects to the development of these nations. The lack of data related to the indicators included in existing frameworks and the disregard for management practices are another setbacks which hinder the accurate implementation of these tools in developing countries.

Moreover, these systems were found to be mainly oriented to their countries of origin and omit most of both the Millennium Development Goals (MDGs) established in the United Nations (UN) Millennium Declaration (UN, 2000) and the Sustainable Development Goals (SDGs) adopted by the UN General Assembly on 25 September 2015 (UN, 2015). MDG 1 (Eradicate Extreme Poverty \& Hunger), MDG 3 (Promote Gender Equality and Empower Women) and MDG 7 (Ensure Environmental Sustainability) should be included in rating systems for infrastructure projects in developing countries. SDGs 4, 5, 11 and 16 address social issues such as the search for education equality in terms of gender and quality, the transformation of cities and human settlements in safe, inclusive and resilient places. The promotion of sustainable economic growth and employment and resilient infrastructure and industrialization are targeted by SDGs 8 and 9 . The governance area, which corresponds to SDGs 12 and 17, involves the use of sustainable consumption and production patterns and the strengthening of the global partnership for sustainable development. 
The scarcity of definitive management guidelines to establish key elements for assessing the degree of sustainability of a project confuses owners, consultants and other stakeholders. The implementation of sustainability management practices and reporting systems is also crucial to meet project goals for sustainable development and measure progress towards the achievement of these aims (FIDIC, 2012).

As a contribution to enhance the field of sustainable rating systems, this paper proposes a methodology and a set of TBL indicators to create a new Sustainable Infrastructure Rating System for Developing Countries (SIRSDEC) through the combination of two multi-criteria decision-making methods: Analytic Hierarchical Process (AHP) and Integrated Value Model for Sustainable Assessment (MIVES). The combination of AHP and MIVES has been used successfully in the past to appraise the contribution to sustainability provided by different construction alternatives (San-Jose Lombera et al., 2010; Pons and Aguado, 2012), to the extent of being included in the Spanish Structural Concrete Standard (EHE-08) (Aguado et al., 2012). AHP is used to weight the elements into which the system is structured according to the opinions returned by a group of international experts regarding their relative importance, whilst MIVES provides value functions to transform indicators measured in different units into a value index (Jato-Espino et al., 2014). SIRSDEC arises as an effective response to the weaknesses detected in current infrastructure rating systems and seeks to create, develop and implement a tool capable of guiding and promoting sustainable development in poorer countries through the implementation of infrastructure projects.

\section{Sustainable Infrastructure in Developing Countries}

The United Nations (UN) created the Human Development Index (HDI), based on the consideration of a series of criteria such as life expectancy, per capita income and literacy rate, to classify countries into categories according to their economic development. Countries with an HDI below 0.8 are generally considered as Developing Countries. UN has 193 member states, of which 53 and 140 are classified as developed and developing countries, respectively. Developing countries include Albania, Bosnia and Herzegovina, Serbia and Macedonia in Europe, Africa, Asia (except Japan, South Korea, Hong Kong, Singapore, Qatar, Brunei and Bahrein) and South America (excluding Chile and Argentine) (UN-Habitat, 2015).

Developing countries require a major increase in infrastructure investment to reduce growth constraints, contribute to urbanization needs and meet their development, inclusion and environmental goals. Global trade plays an outstanding role in countries development and consequently in infrastructure. This includes traditional transport infrastructure such as roads, railways and ports, and information technology infrastructure. World population is expected to increase from 6.1 to 8.1 billion between 2010 and 2030 (UN-Habitat, 2011). Most of this rise corresponds to urban settlements located in developing countries, which accelerates more the need of sustainable urban infrastructure (UN-DESA, 2014).

Infrastructure role is also essential to ensure the sustainability of economies through the limitation of environmental impacts of infrastructure assets, mitigation of Climate Change and fostering of sustainable practices (Ebobisse, 2015). The rise of investment budget has been estimated from $\$ 1$ trillion per year nowadays to approximately $\$ 1.8-2.3$ trillion per year by 2020 , assuming $4 \%$ of Gross Domestic Product (GDP) annual growth rate, which means about 3-8\% of total GDP (Fardoust et al., 2010). In addition, $\$ 200-300$ billion are destined for measures aimed at ensuring lower emissions and more resilience to climate change. Figure 1 depicts pie charts indicating the investment required in 2020 according to regions and sectors. East Asia Pacific (EAP) is expected to require most of this investment, followed by South Asia (SA) and Latin America and The Caribbean (LAC). Regarding the distribution by sectors, basic infrastructure such as Electricity, Water and Transportation monopolize most of the budget. An estimate of 1.4 billion people still has no access to electricity, whilst 0.9 billion do not have 


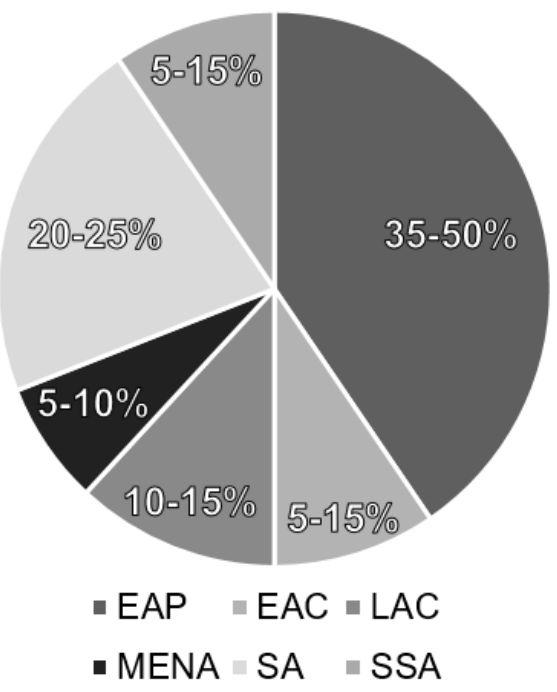

a)

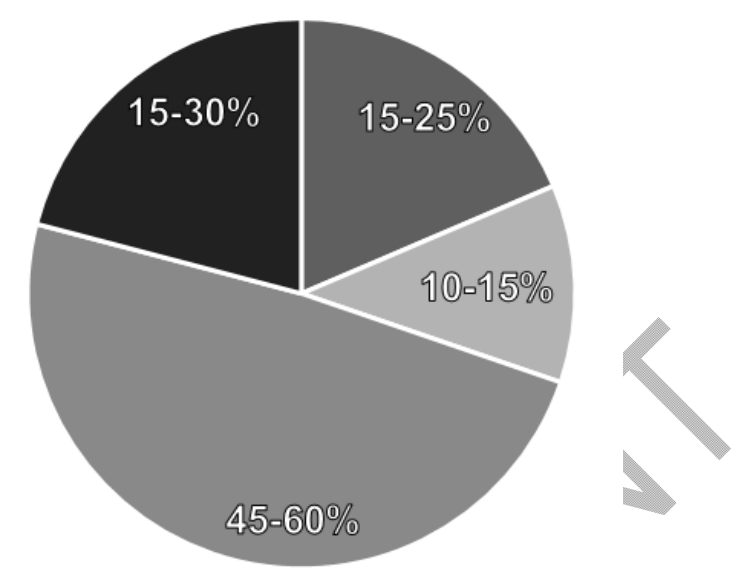

- Transportation = Telecommunication

- Electricity

b)

Figure 1. Estimated annual infrastructure investment in 2020 split by a) Region b) Sector (\$ trillion)

Infrastructure projects have a prominent impact on determining environmental sustainability. Between 10 and $15 \%$ of the required infrastructure investment can be assigned to make such investment sustainable by ensuring lower emissions, higher efficiency and resilience to Climate Change (UNCTAD, 2014). Despite this additional cost, the net effect of these investments is very positive from social, economic and environmental perspectives (UN-DESA, 2015). The rise of economic growth and the change from primary to secondary and tertiary economic industries are evident consequences of infrastructure development, which also reduce levels of inequality and give added social returns to the community (UNOPS, 2012).

An increasing number of international development organizations are managing a wide range of projects in developing countries over the last decades to foster social, economic and environmental development. Amongst them, the role of Multilateral Development Banks (MDBs) is highly remarkable. MDBs delivered a joint statement Commitment to Sustainable Transport during the Rio+20 Conference, with the aim of strengthening the role of transportation infrastructure in sustainable development by providing $\$ 175$ billion of loans and grants to develop projects in developing countries from 2012 to 2022 . At present, more than 200 projects have been approved, including 115 for roads, 39 for urban transport, 24 for rail, 13 for airports and 5 for inland waterway and maritime projects (MDBs, 2015). Furthermore, the MDB Infrastructure Action Plan (MDBs, 2011) reflects extensive analysis and collaboration among the MDBs through a background report on infrastructure issues in third world countries provided to the Group of 20 (G20) in June 2011. This plan describes an ambitious set of initiatives aimed at unlocking the infrastructure project pipeline, in order to enable both increasing the participation and financing in the private sector and improving the efficiency of infrastructure spending.

Despite the huge budget destined for the development of infrastructures in developing countries, no global Sustainability Infrastructure Rating System has been created to manage and monitor them. The Sustainable Transport Appraisal Rating (STAR) framework (Veron-Okamoto et al., 2014), created by the Asian Development Bank and used by the MDBs, includes criteria to assess the social, economic and environmental sustainability of transportation projects. Engineers against Poverty and Arup worked on a Sustainability Poverty and Infrastructure Routine for Evaluation (ASPIRE) (EAP \& ARUP, 2011) that appraises projects qualitatively according to the TBL, but does not rate them. The International 

in 2004 to provide some guidelines about what a sustainable project consists of (FIDIC, 2004).

\section{Methodology}

A literature review was conducted to collect information related to existing Sustainable Infrastructure Rating Systems, multi-criteria decision-making methods, sustainable development goals established by international organizations and needs of developing countries in terms of the TBL. Once the objectives to be achieved by SIRSDEC were established, the decision-making problem was defined according to a hierarchical three-level scheme, usually called decision-making tree, consisting of a series of requirements, criteria and indicators. A questionnaire form was distributed to international experts to collect their opinion regarding the relative importance among the elements in the decision-making tree. The Analytic Hierarchy Process (AHP) was selected to transform the linguistic pairwise comparisons provided by the experts into the weights of requirements, criteria and indicators. The Integrated Value Model for Sustainable Assessments (MIVES) (ETCG, 2015) was proposed to convert the ratings of the indicators across the indicators into value indices reflecting the satisfaction degree they produced. The definition of different feasible alternatives to the decision-making problem allows their appraisal from the perspective of multiple criteria and objectives (Janssen, 1992) and the subsequent determination of their contribution to sustainability. Figure 2 illustrates the research methodology used to conceive SIRSDEC.

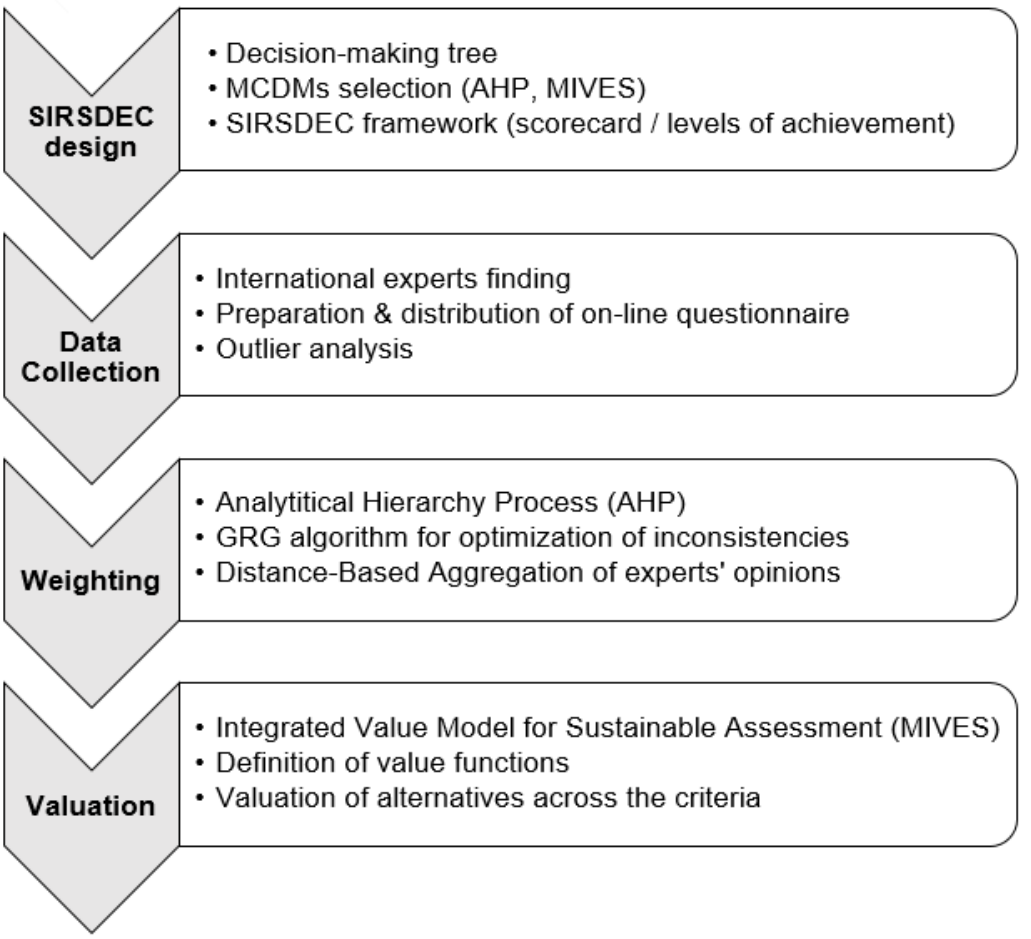

Figure 2. Research methodology developed for this paper

\subsection{SIRSDEC design}

Sustainability assessments consist of the identification, prediction and evaluation of the potential impact of different solutions or alternatives across the TBL (Devuyst, 2000). Developing countries emphasise socio-economic development over environmental aspects when formulating their sustainability agenda (Ugwu and Haupt, 2005). Therefore, the achievement of sustainable development goals in these areas requires a balance among environmental awareness and the specific socio-economic demands of citizens (incomes, employment, shelter, basic services, social infrastructure and transportation) (Hiremath et al., 2013). Consequently, the assessment of sustainability in poorer nations requires the design of decision support tools to facilitate the selection of indicators based on country and location- 
specific needs through the study of the local priorities in relation to the sustainability agenda and the incorporation of international indicators (Diaz-Sarachaga et al., 2016).

Under these premises, SIRSDEC was designed to include indicators mainly referred to Agenda 21 issues (UN, 1992), in order to achieve a balance between the three pillars of sustainable development. Therefore, these indicators focused on the particular context of developing countries and considered all the stages of a long-term project life-cycle such as design, construction, operation, renovation and demolition/reuse. The management dimension was also considered to overcome the existing shortage of guidelines to interconnect the overall goals of sustainable development in poorer countries (Hiremath, 2013). Furthermore, additional overarching features were also taken into account in the selection process of the set of criteria and indicators to characterize SIRSDEC. Amongst them, the relevance of the principles of sustainability reflects the whole performance of the rating system and its orientation to policy issues, which enables identifying the changes required to promote progress towards sustainability goals (Hart, 2006). The breakdown of the SIRSDEC decision-making tree is shown in Table 1, including 4 requirements, 23 criteria and 29 indicators.

Table 1. SIRSDEC decision-making tree

\begin{tabular}{|c|c|c|c|c|c|}
\hline R\# & Requirement & C \# & Criteria & I \# & Indicator \\
\hline \multirow{7}{*}{$\mathrm{R} 1$} & \multirow{7}{*}{ Management } & & & $\mid 1.1 .1$ & ISO 9001 or equivalent \\
\hline & & C1.1 & Internatıonal Standards & $\mid 1.1 .2$ & ISO 14001 or equivalent \\
\hline & & C1.2 & Project Sustainability Management (PSM) plan & 11.2 .1 & Project Sustainability Management plan \\
\hline & & C1.3 & Sustainability Risk Management (SRM) plan & 11.3 .1 & Sustainability Risk Management plan \\
\hline & & C1.4 & Sustainable Procurement plan & I1.4.1 & Sustainable Procurement plan \\
\hline & & C1.5 & Inspection \& Auditing (I\&A) plan & 11.5 .1 & I\&A plan \\
\hline & & C1.6 & Reporting \& Lessons Learned (R\&LL) & 11.6 .1 & Periodic reports distribution \\
\hline \multirow{6}{*}{$\mathrm{R} 2$} & \multirow{6}{*}{ Society } & $\mathrm{C} 2.1$ & Community \& Stakeholders involvement & I2.1.1 & Stakeholders involvement ratio \\
\hline & & $\mathrm{C} 2.2$ & Role of indigenous people & I2.2.1 & Indigenous involvement ratio \\
\hline & & $\mathrm{C} 2.3$ & Equitable development & 12.3 .1 & Gender average wage ratio ( $\mathrm{f} / \mathrm{m})$ \\
\hline & & $\mathrm{C} 2.4$ & Social impacts \& benefits & 12.4 .1 & Population impacted by project \\
\hline & & C2.4 & soctar iminacts a ventems & 12.4 .2 & Settlements area disturbed \\
\hline & & $\mathrm{C} 2.5$ & Cultural Heritage & I2.5.1 & Local cultural assessment \\
\hline \multirow{11}{*}{ R3 } & \multirow{11}{*}{ Environment } & C3.1 & Natural Ecosystem conservation & I3.1.1 & Impacted ecosystem area ratio \\
\hline & & C3.2 & Biodiversity Ecosystem & I3.2.1 & Endangered species ratio \\
\hline & & C3.3 & Greenhouse gases emissions & I3.3.1 & GHG emissions reduction rate \\
\hline & & & Enerav consumntion & I3.4.1 & Energy savings rate \\
\hline & & C3.4 & Energy consump & 13.4 .2 & Renewable energy use rate \\
\hline & & & & |3.5.1 & Fresh water consumption \\
\hline & & C3.5 & vater management & I3.5.2 & Runoff water stored \\
\hline & & C3.6 & Flooding risk & I3.6.1 & Floodplains area \\
\hline & & & Air Quality & I3.7.1 & Air pollutants reduction \\
\hline & & & Waste management & I3.8.1 & Waste production decrease \\
\hline & & 3.8 & vaste management & I3.8.2 & Recycled/reused waste \\
\hline \multirow{4}{*}{ R4 } & \multirow{4}{*}{ Economy } & & Combating poverty & 14.1.1 & Local economic assessment \\
\hline & & C4.2 & Agriculture impacts & 14.2.1 & Farmland area impacted \\
\hline & & C4.3 & Local materials consumption & 14.3.1 & Local materials use rate \\
\hline & & C4.4 & Local employment & 14.4.1 & Local employment rate \\
\hline
\end{tabular}

243 Each of the 23 criteria that forms SIRSDEC corresponds to an objective that infrastructure projects must 244 achieve to be considered "sustainable" in developing countries. As a prerequisite, SIRSDEC has 13 245 mandatory criteria to ensure all projects face key issues related to sustainability in less developed 246 countries. In the domain of management, there are 4 compulsory criteria: International Standards (C1.1), 247 Project Sustainability Management (PSM) plan (C1.2), Sustainable Procurement plan (C1.4), and 248 Inspection \& Auditing (I\&A) plan (C1.5). The social aspect encompasses 3 additional mandatory criteria, 249 such as Community \& Stakeholders involvement (C2.1), Equitable development (C2.3) and Culture 250 Heritage (C2.5). The environmental requirement includes 4 indispensable criteria: Natural Ecosystem 251 conservation (C3.1), Greenhouse gases emissions (C3.3.), Water management (C3.5), and Flooding 
risk (C3.6). Combating poverty (C4.1) and Local employment (C4.4) in the economic requirement complete the set of 13 essential criteria demanded for all projects.

SIRSDEC includes a set of 29 measurable indicators that represent key issues in infrastructure project delivery, in order to monitor the performance, sustainability understanding and appropriate linkage between stakeholders. The management requirement consists of 8 indicators. I1.1.1 evaluates the implementation and maintenance of ISO 9001 (or equivalent) to align project team members with international quality management standards, whilst I1.1.2 plays the same role with ISO 14001 (or equivalent) to fulfil a set of environmental management practices. 11.2.1 rewards the ability to design and implement projects integrating social, environmental and economic aspects. The use of the Sustainability Risk Management (SRM) plan monitored through 11.3.1 targets the identification, assessment, prioritization and implementation of an action plan for sustainability risks. The consideration of the Sustainable Procurement plan scored by I1.4.1 aims to manage procurement and supply chains through the balance of social, economic and environmental aspects. The implementation of the I\&A plan to ensure the compliance of sustainable practices, the distribution of progress reports to stakeholders and the recording \& outreach of lessons learned are the goals sought by I1.5.1, I1.6.1 and 11.6.2, respectively.

Six indicators are considered in the social requirement. 12.1.1 and 12.2.1 assess the degree of involvement of stakeholders and indigenous community in the project with respect to the total affected stakeholders and population. Gender wage equality is evaluated using 12.3.1 as the ratio of average female wages to male salaries. 12.4.1 shows the proportion of population negatively impacted by the infrastructure under analysis over its life-cycle in social, environmental and economic terms. The ratio of housing temporary and/or permanently affected by the project is monitored by 12.4.2. 12.5.1 awards the identification, assessment, management and maintenance of cultural heritage as defined in the United Nations Educational, Scientific and Cultural Organization (UNESCO) (UNESCO, 1972).

The environmental dimension contains 11 indicators affecting the whole life-cycle of the project. I3.1.1 and 13.1.2 reflect the proportion of ecosystem area and endangered species impacted negatively during the development and operation of projects, respectively. 13.3.1 and I3.4.1 appraise the reduction of GHG emissions and used energy with respect to standard estimates. The ratio of consumed fresh water in comparison with available water resources is assessed by 13.5.1, whilst the capability to store runoff is rewarded by 13.5.2. The rate of land area in the project sensitive to suffer damage by flooding is assessed through 13.6.1. 13.7.1 and 13.8.2 award actions taken to decrease air pollutant emissions and waste production in comparison with standard values (NEC, 2001).

287

288

289

290

291

292

293

294

295

296

297

298

299

300

301

302

303

304

The economic requirement is characterized in SIRSDEC through 4 indicators. 14.1.1 rewards the assessment of the economic benefits added by the project that can contribute to reducing levels of poverty and promoting economic growth in the region. The impact of the project on land where permanent crops are located is measured by 14.2.1. Finally, the fostering of local materials and manpower use is appraised by 14.3 .1 and 14.4 .1 , respectively.

SIRSDEC is a system designed to help users to evaluate the sustainability of any infrastructure project developed in developing countries at any stage in their life cycles. The total score of the system amounts 29 points, each of them related to the fulfilment of the objectives measured through the set of indicators, so that each indicator scores in a range between 0 and 1 . There are 13 compulsory criteria that represent 15 points which must be necessarily achieved to pass evaluation. The accomplishment of the remaining indicators can lead to reach the two other levels of achievement considered in SIRSDEC: Pass (15 points), Silver (16 to 22 points) and Gold (22+ points).

Despite SIRSDEC tries to fill the existing gap of sustainability frameworks to rate infrastructure projects in developing countries, some aspects limit its standardized application. SIRSDEC aims to appraise sustainability in all different stages of a project, including operation. Hence, this system requires a 
permanent source of relevant and reliable information which might be difficult to acquire at the present time. Furthermore, no systematic management practices are implemented in these countries, which hinders the use of SIRSDEC as the cornerstone of a general sustainability framework. Finally, although SIRSDEC was originally designed as an easy-to-use tool to be widely deployed worldwide, the specifics of some geographical areas might require the customization and reweighting of indicators in very particular cases.

\subsection{Data collection}

An on-line questionnaire was prepared using Google Forms to collect and summarize the opinions from international leading experts belonging to several countries worldwide in an easy and automatic manner. This approach facilitated the distribution of the survey among a larger number of participants located in different continents and the quick integration of the data received using the same tool. The questionnaire is expected to be sent to more than a hundred of professionals related to the assessment of sustainability, so that a response rate of about $25 \%$ could be considered enough to validate its representativeness. The profiles sought to form the panel of respondents should include international leading experts in the domain of sustainability and environmental assessment systems such as professionals from academia, industry, public development institutions and research organizations.

323

324

325

326

327

328

329

330

The survey was divided into three parts. The first part defined the purpose of each element in the decision-making tree represented in Table 1, guided the respondents about how to fill in the questionnaire and requested some information related to their profile for making statistics. The second section invited the experts to answer several general questions related to sustainability and its assessment, whilst the last part focused on the pairwise comparisons between indicators, criteria and requirements according to questions like "How important is element $i$ with respect to element $j$ ?".

\subsection{Weighting of the elements in the decision-making tree}

Weighting is a key factor in sustainability assessments, since it has a great influence on the overall score reachable by a project (Lee et al., 2002). SIRSDEC has been designed as a generic framework valid for all developing countries, which implies that weighting re-assessment is not necessary for evaluating a project to be implemented in any country included in this category. The comparisons provided by the experts in the last step of the questionnaire were processed to obtain weights of the elements in the decision-making tree using the Analytic Hierarchy Process (AHP) (Saaty, 1980). This method was selected for weighting because of its simplicity and flexibility to be combined with other multi-criteria methods (Vaidya et al., 2006). Table 2 shows the numerical scale considered in the AHP method to quantify a list of pairwise comparisons as that collected from the questionnaires returned by the experts.

Table 2. AHP pairwise comparison scale

\begin{tabular}{llc}
\hline Qualitative evaluation & & Rating \\
\hline Absolutely more important & (AMI) & 9 \\
Much more important & (MMI) & 7 \\
More important & $(\mathrm{MI})$ & 5 \\
Slightly more important & $(\mathrm{SMI})$ & 3 \\
Equally important & $(\mathrm{EI})$ & 1 \\
Slightly less important & $(\mathrm{SLI})$ & $1 / 3$ \\
Less important & $(\mathrm{LI})$ & $1 / 5$ \\
Much less important & $(\mathrm{MLI})$ & $1 / 7$ \\
Absolutely less important & $(\mathrm{ALI})$ & $1 / 9$ \\
\hline
\end{tabular}


The application of the comparison scale shown in Table 2 enables the construction of a $n x n$ reciprocal matrix of pairwise comparisons (Skibniewski et al., 1992). Its consistency is evaluated throughout the maximum matrix eigenvalue $\left(\lambda_{\max }\right)$, so that the matrix is completely consistent when $\lambda_{\max }=n$ and becomes increasingly inconsistent as the eigenvalue grows, according to the consistency ratio (C.R.) defined in Eq. (1).

where C.I. is the consistency index and R.I. is the random consistency index. A matrix is considered consistent when the ratio between C.I. and R.I. is less than 0.1, with C.I. being expressed as in Eq. ¡Error! No se encuentra el origen de la referencia.. The values of R.I. listed in Table 3 represent the average C.I. for 500 randomly generated matrices of the same order.

$$
\text { C. I. }=\frac{\lambda-n}{n}
$$

Table 3. Random consistency index

\begin{tabular}{lccccccccc}
\hline Matrix size $(\boldsymbol{n})$ & 2 & 3 & 4 & 5 & 6 & 7 & 8 & 9 & 10 \\
\hline R.I & 0.00 & 0.58 & 0.90 & 1.12 & 1.24 & 1.32 & 1.41 & 1.45 & 1.49 \\
\hline
\end{tabular}

The method proposed by Jato-Espino et al. (2016), which is based on the Generalized Reduced Gradient (GRG) algorithm (Abadie et al., 1968) and an aggregation system according to the proximity between the judgments of each pair of respondents, was used to adjust possible inconsistencies in the questionnaires and synthetize they all into a consensual set of weights.

Therefore, if $[A]$ is the inconsistent comparison matrix related to a set of criteria $C_{j}=\left\langle C_{1}, C_{2}, \ldots, C_{n}\right\rangle$ and $[\mathrm{A}]^{\prime}$ is the objective consistent matrix being sought, the algorithm minimizes the differences between the upper right triangles of both matrices to fulfil Eq. (2), with the limitation of remaining within the corresponding lower and upper threshold values of the AHP comparison scale. The differences between both matrices are measured using the Root Mean Square Error (RMSE) (Chai et al., 2014). A logarithmic scale is applied to equalize the differences between lower and higher thresholds, so that the minimization problem is expressed as shown in Eq. (3).

$$
\begin{array}{lll}
\text { Minimize } & \sqrt{\frac{1}{\mathrm{n}} \sum_{\mathrm{i}, \mathrm{j}=1}^{\mathrm{n}}\left(\ln \mathrm{a}_{\mathrm{ij}}-\ln \mathrm{a}_{\mathrm{ij}}^{\prime}\right)^{2}} & 376 \\
& 377 \\
\text { subject to: } & \text { C. R. } \leq 0.1 & 378 \\
& \ln \mathrm{a}_{\mathrm{ij}}^{\mathrm{LT}}<\ln a_{i j}^{\prime}<\ln \mathrm{a}_{\mathrm{ij}}^{\mathrm{UT}} & 38(3) \\
& 381 \\
& 382 \\
& & 383
\end{array}
$$

384 The Euclidean distance, a common metric to assess similarities between datasets (Xing et al., 2003), is proposed to evaluate the affinity between the judgments provided by the respondents, so that a symmetric $n x n$ matrix [N] is obtained from the Euclidean distances between each pair of experts, with $n$ being the number of respondents. Therefore, the weight for each expert is determined as the inverse of the sum of the distances from each respondent to the remaining ones.

These weights were aggregated using the geometric mean, which has been proven to be the proper method to integrate a set of $n$ individual opinions into a unique agreed judgment $\left(\mathrm{a}_{\mathrm{ij}, \mathrm{c}}\right)$ as the $n^{\text {th }}$ root of their product (Aczél et al., 1983), (Aczél et al., 1987). Finally, the weights $w_{\mathrm{i}}$ of the elements in the 
normalization $\left(\mathrm{a}_{\mathrm{ij}, \mathrm{cn}}\right)$ of the values in the consensual comparison matrix formed of $n$ values of $\mathrm{a}_{\mathrm{ij}, \mathrm{c}}$ as 395 shown in Eq. (4):

$$
\mathrm{a}_{\mathrm{ij}, \mathrm{cn}}=\frac{\mathrm{a}_{\mathrm{ij}, \mathrm{c}}}{\sqrt{\sum_{\mathrm{i}=1}^{\mathrm{n}} \mathrm{a}_{\mathrm{i}, \mathrm{c}}{ }^{2}}}
$$

$$
\mathrm{w}_{\mathrm{i}}=\frac{\sum_{\mathrm{i}=1}^{\mathrm{n}} \frac{1}{\sqrt{\sum_{\mathrm{i}=1}^{\mathrm{n}} \mathrm{a}_{\mathrm{ij}, \mathrm{c}}}}}{\sum \sum_{\mathrm{i}=1}^{\mathrm{n}} \frac{1}{\sqrt{\sum_{\mathrm{i}=1}^{\mathrm{n}} \mathrm{a}_{\mathrm{ij}, \mathrm{c}}}}}
$$

\subsection{Valuation of indicators}

MIVES is a multi-criteria decision-making (MCDM) method that emerged as the result of initial researches conducted by three Spanish institutions: Universidad del País Vasco (UPV), Universitat Politècnica de Catalunya (UPC) and LABEIN-Tecnalia. MIVES was developed through two projects approved in public competitions organized under the Spanish National Research Plan, using value analysis as a platform for decision-making for evaluating alternatives and evaluating sustainability quantitatively (San-Jose et al., 2010). Value functions are the key elements of MIVES, since they enable the transformation of the ratings of alternatives across the indicators, which are commonly measured in different units, into non-dimensional values in the range between 0 and 1 that represent the degree of satisfaction they provide.

Value functions are defined by five parameters $\left(K_{i}, C_{i}, X_{\min }, X_{\max }\right.$ and $\left.P_{i}\right)$ which determine four different shapes to model these transformations: linear, concave, convex and S-shape. Figure 3 illustrates the parameters to be taken by these functions, as well as the shapes in which they result. S-shape functions include the most relevant increase in satisfaction in the central zone of the curve. On the contrary, convex and concave curves reveal increases in satisfaction in areas close to $\mathrm{X}_{\min }$ and $\mathrm{X}_{\max }$, depending on whether the function is increasing or decreasing. Linear functions consist of a steady increasing or decreasing of satisfaction regardless of the value of the abscissa.

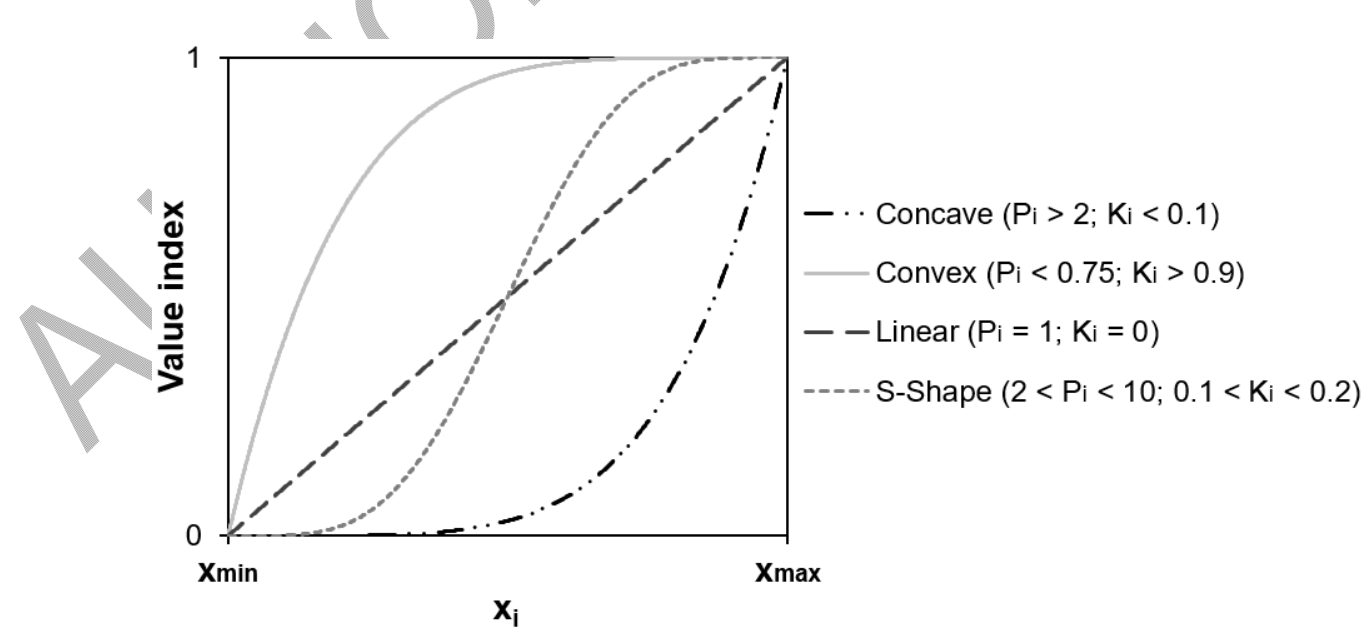

Figure 3. Different shapes and parameters of MIVES value functions

Value functions for increasing indicators are calculated according to Eqs. (6) and (7). If the value of the indicator decreases as its rating increases, $\mathrm{X}_{\min }$ is replaced by $\mathrm{X}_{\max }$ in both formulations. 


$$
\mathrm{V}_{\text {ind }}=\mathrm{B} *\left[1-\mathrm{e}^{-\mathrm{K}_{\mathrm{i}} *}\left(\frac{\left|\mathrm{X}-\mathrm{X}_{\min }\right|}{\mathrm{C}_{\mathrm{i}}}\right)^{\mathrm{P}_{\mathrm{i}}}\right]
$$

where $\mathrm{X}_{\min }$ is the abscissa for the minimum value reachable by the indicator, $\mathrm{X}$ is the actual rating of the alternative with respect to the indicator, $P_{i}$ is the form factor and $C_{i}$ and $K_{i}$ are the abscissa and ordinate in the inflection point of the curve, respectively. $\mathrm{B}$ is an adjusting to ensure that value indices remain in the range $[0,1]$ and is determined by Eq. (7):

$$
\mathrm{B}=\left[1-\mathrm{e}^{-\mathrm{K}_{\mathrm{i}} *}\left(\frac{\left|\mathrm{X}_{\max }-\mathrm{X}_{\min }\right|}{\mathrm{C}_{\mathrm{i}}}\right)^{\mathrm{P}_{\mathrm{i}}}\right]^{-1}
$$

where $\mathrm{X}_{\max }$ is the abscissa for the maximum value the indicator might achieve. The overall sustainability index $\mathrm{V}_{\mathrm{i}}$ of an alternative is calculated through the aggregation of the value indices from the lower (indicators) to the upper (requirements) levels of the decision-making tree:

$$
\mathrm{V}_{\mathrm{i}}=\sum_{\mathrm{j}=1}^{\mathrm{m}} \mathrm{V}_{\mathrm{ij}} * \mathrm{~W}_{\mathrm{j}}
$$

where $\mathrm{V}_{\mathrm{ij}}$ and $\mathrm{W}_{\mathrm{j}}$ are the sustainability index and weight for an alternative in relation to the $i$ level in the decision-making tree and $m$ is the number of elements in each level forming the decision-making tree.

Binary stepped value functions ( 0 or 1$)$ were assigned to those indicators that does not consider intermediate values and are simply evaluated according to whether their purpose is met or not (I1.1.1, I1.12, I1.2.1, I1.3.1, I1.4.1, I1.5.1, I1.6.1, I1.6.2, I2.5.1 and I4.1.1). The parameters to characterize the remaining indicators using the value functions depicted in Figure 3 were defined from data found in international development organizations such as the World Bank, the International Labour Office (ILO), the United Nations Environment Programme (UNEP), the United Nations Development Programme (UNDP), the United Nations Human Settlements programme (UN-HABITAT) and the United Nations Educational Scientific and Cultural Organization (UNESCO). Since these data were collected by international agencies to monitor specific metrics which can differ from the goals sought by some of the

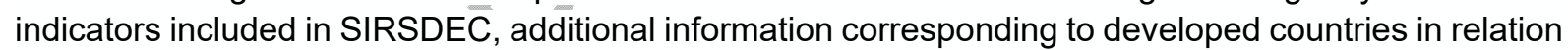
to similar parameters could be considered instead. Furthermore, data included in existing sustainable rating systems were another reference to be used in the definition of value functions if international data did not positively correlate to the set of indicators considered in SIRSDEC.

\section{Conclusions}

This article presents the methodology to develop a rating tool to appraise infrastructure projects in developing countries (SIRSDEC) according to their contribution to the Triple Bottom Line through the combination of two multi-criteria analysis methods such as AHP and MIVES. In contrast to existing rating systems, which weight criteria and indicators related to sustainability by direct allocation, SIRSDEC uses the judgments received from international experts to determine these weights through an on-line questionnaire based on the AHP pairwise comparison scale. The contribution of infrastructure projects in developing countries to sustainable development across the weighted indicators and criteria is assessed using the value functions provided by MIVES, which facilitate the standardization of indicators and their subsequent unrestricted integration into an overall sustainable value index.

SIRSDEC emphasizes the role of social and economic aspects, including the management dimension as the linkage between the three pillars of sustainable development. In contrast to existing overarching frameworks, which are substantially oriented to environmental issues, the particular context of poorest economies requires balancing the importance of the criteria and indicators belonging to these four 
aspects, in order to conduct a feasible sustainability assessment. In this line, the proposed tool has established specific criteria and indicators to enhance social and economic impacts of projects on communities. Hence, in the absence of scoring guidelines for developing countries, SIRSDEC provides an effective decision-making tool to be used by public and private not-for-profit organizations, in order to promote the sustainable development of poorer nations through the assessment of infrastructure projects.

Indicators derived from Agenda 21 and the Millennium and Sustainable Development Goals, which are the flagship of sustainable development assessment, have been found to not evaluate properly the sustainable performance in less developed countries. Information collected from public development institutions, United Nations agencies and development banks are mainly focused on health and education, whilst only a minority of indicators refers to relevant factors concerning the Triple Bottom Line. This circumstance hinders the definition of the value functions required to characterize the set of indicators forming SIRSDEC. Consequently, new additional indicators related to social, economic and environmental domains should also be considered in the short time by public institutions to monitor the achievement of sustainable development goals in developing countries accurately.

SIRSDEC can be considered as the starting point of future researches. UN agencies and multilateral banks require effective rating systems to tangibly assess how the large number of infrastructure projects in which they invest every year in poorer countries contribute to sustainable development. The international standardisation of sustainable development indicators involving a balanced consideration between social, economic and environmental aspects, as well as the inclusion of the management dimension as the linkage between them, are the key factors to consider in the analysis of sustainable development. The growing relevance of urbanization trend in developing countries brings a new opportunity to promote the application of frameworks like SIRSDEC for measuring sustainable urban development.

\section{References}

Abadie $\mathrm{J}$ and Carpentier $\mathrm{J}$ (1968) Generalization of the Wolfe reduced gradient method to the case of nonlinear constraints, 37-47.

Aczél J, Saaty TL (1983) Procedures for synthesizing ratio judgements. J. Math. Psychol. Vol. 27, 93102.

Aczél J, Alsina C (1987) Synthesizing judgements: a functional equations approach. Mathematical Modelling. Vol. 9, 311-320.

ADB Sustainable Development Working Paper Series, № 31. January 2014. Asian Development Bank. Aguado A, Caño AD, De la Cruz MP, Gomez D and Josa A (2012) Sustainability assessment of concrete structures within the Spanish structural concrete code. Journal of Construction Engineering and Management 138 (2), pp. 268-276.

Bhattacharya A, Romani M and Stern N (2012) Infrastructure for development: meeting the challenge. Policy paper. Centre for Climate Change Economics and Policy Grantham Research Institute on Climate Change and the Environment in collaboration with Intergovernmental Group of Twenty-Four.

BRE (2014) BREEAM (Building Research Establish Environmental Assessment Method). Retrieved from https:// www.breeam.com on $28^{\text {th }}$ December 2015.

BRE Group (2015). CEEQUAL. Retrieved from http://www.ceequal.com on $19^{\text {th }}$ January 2016.

Chai T, Draxler RR (2014) Root mean square error (RMSE) or mean absolute error (MAE)? -Arguments against avoiding RMSE in the literature. Geoscientific Model Dev. Vol. 7, 1247-1250.

Devuyst D (2000) Linking impact assessment and sustainable development at the local level: the introduction of sustainability assessment systems. Sustainable Development, 8(2), 67-78.

Diaz-Sarachaga JM, Jato-Espino D, Alsulami B and Castro-Fresno D (2016) Evaluation of existing sustainable infrastructure rating systems for their application in developing countries. Ecological Indicators 71, 491-502. 
EAP, Engineers against poverty \& ARUP (2011) ASPIRE A Sustainability Poverty and Infrastructure Routine for Evaluation. Research and Development. http://www.engineersagainstpoverty.org/documentdownload. axd?documentresourceid=29 EAP, Engineers against poverty \& ARUP (2011) ASPIRE A Sustainability Poverty and Infrastructure Routine for Evaluation. User Manual. Retrieved from https://www.oasyssoftware.com/media/Manuals/Latest Manuals/aspire1.1 manual.pdf Ebobisse A (2015) The IFC Global Infrastructure Project Development Fund. IFC Infraventures, Washington.

ETCG (2015) Integrated Value Model for Sustainable Assessments (MIVES). Retrieved from https://www.etcg.upc.edu/pri/mives on 4th November 2015. FIDIC, International Federation of Consulting Engineers (2004) Project Sustainability Management Guidelines. Retrieved from http://fidic.org/books/project-sustainability-management-guidelines-2004. FIDIC, International Federation of Consulting Engineers (2012) The State of the World Report 2012 Sustainable Infrastructure. http://fidic.org/sites/default/files/sow2012-0822-electronic.pdf

Fardoust S, Yongbeom K and Paz-Sepulveda C (2010) Post-crisis Growth and Development: A Development Agenda for the G-20. World Bank Publications.

Gibberd J (2005) Assessing sustainable buildings in developing countries - the sustainable building assessment tool (SBAT) and the sustainable building lifecycle (SBL). Proceedings of the world sustainable building conference. Pages 1605-12.

Hart M (2006) Guide to sustainable community indicators (Second ed.). West Hartford, CT: Sustainable Measures.

Hiremath RB, Balachandra P, Kumar B, Bansode SS. and Murali J (2013). Indicator-based urban sustainability- a review. Energy for Sustainable Development 17(6), 555-563.

IBEC (2011) CASBEE (Comprehensive Assessment System for Building Environmental Efficiency). Retrieved from https://www.ibec.or.jp/CASBEE/english/ on $12^{\text {th }}$ January 2016.

ISCA (2012). IS (Infrastructure Sustainability Rating Tool). Retrieved from http://www.isca.org.au on $12^{\text {th }}$ ISI (2012). ENVISION. Retrieved from http://www.sustainableinfrastructure.org on $23^{\text {rd }}$ November 2015. December 2015.

Janssen R (1992) Multi-objective Decision for Environmental Management. Kluwer Academic, Dordrecht.

Jato-Espino D, Castillo-Lopez E, Rodriguez-Hernandez J, Canteras-Jordana JC (2014) A review of application of multi-criteria decision making methods in construction. Automation in Construction 45, pp. 151-162.

Jato-Espino D, Indacoechea-Vega I, Gaspar L and Castro-Fresno D (2016) Decision support model for the selection of asphalt wearing courses in highly-trafficked roads. Expert Systems with Applications. Under review.

Lee WL, Chau CK, Yik FWH, Burnett J and Tse MS (2002) On the study of the credit-weighting scale in a building environmental assessment scheme. Building and Environment 37, 1385-1396. Litman T (2015) Well measured: Developing indicators for Sustainable and Liveable Transport Planning. Retrieved from http://www.vtpi.org/wellmeas.pdf

MDBs, Multilateral Development Banks (MDB) working Group on Infrastructure (2011) Infrastructure Action Plan. Paper 65561 v1. World Bank Publications.

MDBs, Multilateral Development Banks (MDB) Working Group on Sustainable Transport (2015) Progress Report (2013-2014). United Nations Sustainable Development Knowledge Platform. Retrieved from www.sustainabledevelopment.un.org.

NEC, National Emission Ceilings for certain pollutants (2001) Directive 2001/81/EC of the European Parliament and the Council on National Emission Ceilings for certain pollutants. Retrieved from http://eur-lex.europa.eu/legal-content/EN/TXT/?uri=celex\%3A32001L0081http://eur-lex.eu

Pons $O$ and Aguado A (2012) Integrated value model for sustainable assessment applied to technologies used to build schools in Catalonia, Spain. Building and Environment 53, 49-58.

Saaty TI (1980) The Analytic hierarchy process: Planning, priority setting, resource allocation. McGrawHill. 
San-Jose Lombera JT and Garrucho Aprea I (2010) A system approach to the environmental analysis of industrial buildings. Building and Environment 45, 673-683. Journal of Construction Engineering and Management 118 (3), 577-593. Ugwu $\mathrm{OO}$ and Haupt TC (2005) Key performance indicators for infrastructure sustainability - a comparative study between Hong Kong and South Africa. Journal of Engineering, Design and Technology, 3(1), 30-43.

UN, United Nations (1992) Rio Declaration on Environment and Development. The United Nations Conference on Environment and Development. Rio de Janeiro.

UN, United Nations (1992) Agenda 21 Contents. United Nations Conference on Environment \& Development. Rio de Janeiro. 3 to 14 June 1992 . Retrieved from https://sustainabledevelopment.un.org/content/documents/Agenda21.pdf

UN, United Nations (2000) UN Millennium Declaration. Millennium Summit. www.unmilleniumproject.org UN, United Nations (2015) Transforming our World: the 2030 Agenda for Sustainable Development. Retrieved from http://www.un.org/ga/search/view doc.asp?symbol=A/RES/70/1\&Lang=E

UNCTAD, United Nations Conference on Trade and Development (2014) World Investment report in 2014. Investing in the SDGs: An Action Plan. New York and Geneva. Retrieved from http://unctad.org/en/PublicationsLibrary/wir2014 en.pdf

UN-DESA, United Nations Department of Economic and Social Affairs (2014) World Urbanization Prospects. The 2014 Revision. Highlights. New York. Retrieved from https://esa.un.org/unpd/wup/Publications/Files/WUP2014-Highlights.pdf

UN-DESA, United Nations Department of Economic and Social Affairs (2015) World Population Prospects. Key findings and advance tables. 2015 Revision. Retrieved from https:/lesa.un.org/unpd/wpp/Publications/Files/Key Findings WPP 2015.pdf

UNESCO, United Nations Educational, Scientific and Cultural Organization (1972) The Convention for the Protection of the World Cultural and Natural Heritage. Paris. Retrieved from http://whc.unesco.org/en/convention/

UN-Habitat, United Nations Habitat (2011) Infrastructure for Economic Development and Poverty Reduction in Africa. Nairobi. Retrieved from http://www.uncsd2012.org/content/documents/UNHabitatReport.pdf

UN-Habitat, United Nations Habitat (2015) E-Governance and Urban Policy Design in Developing Countries. Retrieved from http://unhabitat.org/books/e-governance-and-urban-policy-design-indeveloping-countries/

UNOPS, United Nations Office for Project Services (2012) UNOPS Policy for sustainable infrastructure. https://www.unops.org/SiteCollectionDocuments/Multimedia/Rio/unops policy for sustainable infrastr ucture.pdf

USGBC (2009) LEED (Leadership in Energy and Environmental Design). Retrieved from https:// www.usgbc.org/leed on 10th February 2016.

Vaidya OS and Kumar S (2006) Analytic hierarchy process: An overview of applications. European Journal of Operational Research, 169 (1), 1-29.

Veron-Okamoto A and Sakamoto K (2014) Toward a Sustainability Appraisal Framework for Transport. Viñolas B, Cortes F, Marques A, Josa A and Aguado A (2009) MIVES: Modelo Integrado de Valor para evaluaciones de sostenibilidad. II Congres Internacional de Mesura i Modelitzacion de la Sostenibilitat (ICSMM), Barcelona.

Wolfe P (1963) Methods of nonlinear programming in: Graves RL, Wolfe P (Eds.) (1963) Recent Advances in Mathematical Programming. McGraw-Hill, New York (U.S.), pp. 67-86.

Xing EP, Ng AY, Jordan MI, Russell S (2003) Distance metric learning, with application to clustering with side-information. Adv. neural inf. process. syst.

Yeniay $\mathrm{O}$ (2005) A comparative study on optimization methods for the constrained nonlinear programming problems. Math. Probl. Eng. Pages 165-173. 